\title{
OS INDÍGENAS E OS OCIDENTAIS: buscando as diferenças através das semelhanças*
}

\section{Carmem Arias}

\section{Graduada em Geografia e em Ciências Sociais.}

Com o presente artigo pretendemos apresentar algumas reflexões sobre aquela que pode ser chamada de "a singularidade humana", ou seja, a capacidade de simbolizar. Desta forma, ao estudarmos a questão, tentaremos demonstrar que há uma universalidade das mentes humanas e que é graças a essa semelhança psíquica que os homens desenvolvem suas capacidades simbólicas. Logo, tendo em vista que a semelhança entre os homens se encontra exatamente no poder que os mesmos têm de diferir, o nosso principal objetivo é chamar a atenção para o fato de que a diversidade cultural é algo característico da humanidade, e que, vale dizer, não existem raças superiores ou inferiores e sim culturas diferentes.

Palavras-chave: capacidade de simbolização; cultura; "primitivos"; "civilizados"; sociodiversidade cultural indígena no Brasil; noção de pessoa; fabricação do corpo.

\section{INTRODUÇÃO}

$\mathbf{P}$ ara discorrer sobre alguns aspectos referentes aos povos indígenas brasileiros, faz-se necessário apresentar um pequeno apanhado histórico dos principais estudos realizados sobre parentesco, além de abordar os critérios adotados para definir a identidade étnica, a questão da demografia indígena e a questão da sociodiversidade cultural indígena no Brasil, reportando, sobretudo, à noção de pessoa e à fabricação do corpo vigentes em algumas das sociedades indígenas brasileiras.

Um dos argumentos apresentados por GOULD (1978, p.44), ou seja, a idéia de que a semelhança entre os homens se encontra na capacidade que os mesmos têm de simbolizar, constituirá o nosso eixo central de análise. Em outras palavras, o que pretendemos enfatizar é que, entre os humanos, $o$ aspecto que mais chama a atenção é o seu desenvolvimento sociocultural, o qual decorre da sua capacidade de simbolização, sendo esta, portanto, a diferença fundamental que os homens apresentam em relação aos demais primatas. Para LÉVI-STRAUSS (1967), por sua vez, estamos imersos na linguagem, pois a mesma se constitui um fenômeno social: a linguagem humana é diferente da linguagem dos demais animais pelo fato de que apenas o homem possui a capacidade de simbolizar, sendo este, portanto, o limite que afasta o homem dos demais seres, e ao mesmo tempo o impulsiona na direção de um rico sistema cultural. Os demais animais se comunicam, entretanto, apenas o homem consegue relacionar linguagem e pensamento, sendo essa capacidade de simbolização a responsável pela passagem da natureza para a cultura, já que é graças aos símbolos que o homem consegue explicar ou se referir a algo que não está presente.

Assim, tendo em vista que o homem é, eminentemente, um animal que aprende, a cultura é constantemente criada, transmitida e recriada/reelaborada, ou seja, a cultura não é estática, está sempre em mudança. Logo, visto que concebemos a cultura como um processo de criação, internalização e recriação de sistemas simbólicos, podemos afirmar que ela se dá de forma diferenciada tanto em sociedades diferentes como numa mesma sociedade, pois, conforme nos ensina RODRIGUES (1989, p.59), sendo os homens seres culturais, o que de mais semelhante existe entre eles é exatamente o poder de diferir. Abandonaremos, dessa forma, qualquer idéia de que os homens ditos "primitivos" sejam seres dotados de uma unidade psicológica inferior.

\footnotetext{
* O texto é uma versão modificada de um trabalho apresentado para avaliação à disciplina Antropologia do Brasil Indígena, ministrada pela professora Regina Muccillo, no curso de graduação em Ciências Sociais da UEL, durante o ano de 1998.
} 
HISTÓRICO DOS PRINCIPAIS ESTUDOS SOBRE OS POVOS INDÍGENAS NO BRASIL

De acordo com as argumentações de MELATTI (1984), os estudos de caráter etnológico no Brasil tiveram seu início com o descobrimento e foram incrementados com a chegada da família real. Num primeiro momento, tivemos os cronistas e os navegadores que registravam as suas observações pessoais, sendo que eles estavam preocupados em descrever os costumes dos índios, mas, a partir de uma ótica eurocêntrica, etnocêntrica e evolucionista.

A partir de meados do século XIX, alguns brasileiros se incumbiram de tarefas de caráter etnológico, sendo que quase todos eles eram autodidatas em antropologia. Um desses pesquisadores foi o poeta indianista Antônio Gonçalves Dias. Cabe ressaltar que, nesse período, estava em pauta a preocupação com o destino dos povos e com a formação do povo brasileiro.

Nos anos 20 e 30 do presente século, foram abandonadas as preocupações evolucionistas e difusionistas. Entre os anos 30 e 50, dentre os principais fatos ocorridos estão a criação da Universidade de São Paulo e da Universidade do Brasil (no Rio de Janeiro), sendo que, a partir de então, começaram a aparecer estudos que denotam uma preocupação com a sociedade brasileira como um todo (dentre os principais denominadores dessa concepção estão Oliveira Viana, Gilberto Freyre e Sérgio Buarque de Holanda); também têm início os estudos de mudança social, mudança cultural e aculturação (como exemplo, podemos citar Roger Bastide, Ruy Coelho, Herbert Baldus, Darcy Ribeiro, entre muitos outros). Posteriormente, passou a predominar a abordagem funcionalista no estudo das culturas e das sociedades indígenas (dentre os trabalhos deste período destacam-se os de Florestan Fernandes). Nos anos 60, a etnologia começa a passar, no Brasil, por significativas modificações: o enfoque volta-se para os estudos sobre ficção interétnica e etnicidade; as sociedades indígenas passam a ser vistas como totalidades socioculturais; e a mitologia e o ritual passam a ser vistos como sistemas ativos (devemos assinalar que um dos principais representantes desse período foi o antropólogo Claude Lévi-Strauss, o qual tem, mesmo atualmente, uma forte influência na produção etnológica brasileira).

\section{HISTÓRICO SOBRE OS ESTUDOS DE PARENTESCO NO BRASIL}

Com base em um levantamento dos estudos realizados até então sobre parentesco no Brasil, LARAIA (1987) apresenta uma noção geral da natureza da produção científica sobre o parentesco entre os índios brasileiros, sendo que, segundo ele, a moderna antropologia brasileira está ciente de que o parentesco, especialmente nas chamadas sociedades simples, é um dos aspectos mais importantes da organi- zação social, pois, a busca da compreensão do parentesco tem sido, a partir da segunda metade deste século, uma das grandes preocupações da antropologia brasileira.

Segundo o autor, a antropologia brasileira pode ser dividida em dois períodos: o primeiro, que vai até a metade deste século (século XX), onde predomina o pouco interesse pelos estudos do parentesco e enquanto ainda existe a hegemonia de pesquisadores de formação autodidática; e o segundo período, ainda em andamento, o qual é marcado por um maior interesse pelos estudos de parentesco.

No primeiro período, destaca-se Curt Nimuendajú, o primeiro antropólogo brasileiro a se preocupar com o tema do parentesco. Darcy Ribeiro, Roberto Cardoso de Oliveira e Lévi-Strauss, destacam-se nos anos 50. A década de 60, por sua vez, caracterizou-se pela influência da antropologia americana. Recentemente, contudo, Laraia assinala que o parentesco não tem sido uma importante preocupação para os novos pesquisadores, pelo menos no que tange aos grupos Tupi.

\section{OS POVOS INDÍGENAS NO BRASIL}

CUNHA (1983, p.96-100) comenta sobre os antigos critérios pelos quais se decidia se uma comunidade era ou não indígena, e também apresenta o critério que a antropologia social reconhece atualmente como verdadeiro. Dessa forma, a autora afirma que o primeiro critério foi o de raça, ou seja, durante muito tempo, a definição de um grupo étnico foi feita pela biologia. Entretanto, segundo ela, esse critério das características físicas não serve para definir, pois desemboca na idéia de "pureza racial".

Após a Segunda Guerra Mundial, o critério passou a ser o da cultura: um grupo étnico seria definido como aquele que compartilhasse dos mesmos valores, formas e expressões culturais, estando implícita, portanto, a idéia de que a cultura seria algo estático, ou seja, desembocava na idéia de que existia uma "pureza cultural".

Por outro lado, de acordo com o critério vigente atualmente, os grupos étnicos são definidos enquanto "formas de organização social em populações cujos membros se identificam e são identificados como tais pelos outros, constituindo uma categoria distinta de outras categorias da mesma ordem." (CUNHA, 1983, p.98-99) Portanto, segundo BARTH, o critério adequado é o da identidade étnica, sendo que, de acordo com esse critério, "o foco de pesquisa (...) passa a centrar-se (...) nas fronteiras sociais do grupo, e não mais na cultura que essas fronteiras encerram." (apud CUNHA, 1983, p.100)

De acordo com RICARDO (1995, p.29-30), há uma imensa sociodiversidade nativa contemporânea dos povos indígenas no Brasil, entretanto, não se sabe ao certo sequer quantos povos ou quantas línguas nativas existem. Dessa forma, o (re)conhecimento, ainda que parcial dessa diversidade, não ultrapassa os restritos círculos acadêmicos especializados. Conseqüientemente, podemos afirmar, segundo RICARDO (idem, p.29-30), que tal realidade é uma decorrência de dois fatos facilmente constatados no país: são 
poucos os espaços para a expressão diretamente indígena no cenário cultural e político do país; e sabemos pouco sobre os povos indígenas que vivem no Brasil contemporâneo, bastando, para confirmar tal idéia, mencionar que das 206 etnias (das mais de mil que, segundo estimativas, existiam quando da chegada dos colonizadores europeus) e das cerca de 170 línguas nativas existentes hoje no Brasil, talvez apenas metade tenha sido pesquisada, resultando numa bibliografia especializada, cuja maior parte não foi publicada ou é acessível apenas em língua estrangeira. Os povos indígenas que viviam no que veio a se chamar Brasil eram ágrafos $\mathrm{e}$ atualmente a maioria deles não domina a leitura e a escrita. Assim, devido ao fato de que muitos desses povos nativos não se expressam em português e não foram pesquisados por antropólogos e lingüistas, e outros tantos vivem "isolados", há uma brecha para todo o tipo de confusão ortográfica e semântica, ou seja, há uma grande variabilidade na maneira de grafar os nomes das etnias indígenas e uma grande confusão quanto ao significado dos nomes das etnias nativas. (RICARDO, 1995, p.32 e 34)

Com base nos dados do Programa Povos Indígenas no Brasil-CEDI, nov./94, RICARDO (1995, p.46) informanos que a população indígena total no Brasil é de cerca de $270 \mathrm{mil}$, isto é, $0,2 \%$ da população nacional, sendo que a maior parte desses povos indígenas, do ponto de vista demográfico, é formada por microssociedades, ou seja, dos 206 povos indígenas no Brasil, 83 (40\%) têm uma população de até 200 indivíduos.

Também enfocando essa questão da demografia indígena, RAMOS (1995, p.47-48) assinala que, em decorrência das penetrações dos brancos, a antiga densidade demográfica foi-se diluindo, sendo que, apenas no Brasil, a população indígena caiu de uns 3 a 5 milhões em 1500, quando do descobrimento, para os atuais 200 e poucos mil índios. Desta forma, de acordo com a autora, a feição demográfica mais comum nas comunidades indígenas é a de trinta e sessenta habitantes, havendo, é óbvio, uma grande variação em torno desses números, dependendo da região e das condições de contato.

GOMES (1991, p.16) também analisa alguns dados demográficos referentes aos povos indígenas no Brasil e comenta que num período de menos de 500 anos cerca de 95\% da totalidade dessa população desapareceu (ou seja, eram 5 milhões de índios antes da colonização do país, sendo que, de acordo com os dados apresentados por esse autor, em 1991, eram apenas cerca de 230 mil índios no território brasileiro). Portanto, a esse respeito, ele é taxativo:

"Não somente morreram e foram mortos milhões de
seres humanos, como se extinguiram para sempre
mais de cinco centenas de povos específicos, de
etnias, de culturas humanas que eram produto de mi-
lhares de anos de evolução e adaptação ao meio am-
biente físico e social em que viviam." (GOMES, 1991,
p.16)

Um importante aspecto e que, portanto, não deve ser menosprezado, é o da diversidade cultural indígena. Assim, de acordo com RAMOS (1995, p.11), tentar caracterizar em bloco as sociedades indígenas é correr o risco de generalizar sobre uma realidade que, apesar de tudo, ainda é altamente diversificada: "Não há duas sociedades indígenas iguais. Mesmo quando ocupam zonas ecológicas semelhantes, elas mantêm sua individualidade, tanto no plano das relações sociais como no campo simbólico." Nesta perspectiva, a autora complementa seu argumento afirmando que, quando comparados às populações das nações nas quais estão encravados, esses povos indígenas apresentam alguns denominadores comuns que os diferenciam delas. (RAMOS, 1995, p.11)

A conquista (ou melhor, a "invasão") européia teve o efeito de erradicar muitas das diferenças sócio-políticas que existiam: tudo indica que a "invasão" européia provocou uma depopulação em massa e produziu uma certa uniformização cultural, destruindo - parcialmente pelo menos - a grande diversidade que existia há 500 anos na América do Sul. (RAMOS, 1995, p.9-10)

Todavia, tanto o acompanhamento que o Programa Povos Indígenas no Brasil fez da questão nos últimos 20 anos (apud RICARDO, 1995, p.46-47), como também os estudos de GOMES (1971), apresentam dados mais animadores, pois indicam que a população indígena total no Brasil vem aumentando gradativamente, pela primeira vez desde 1500. GOMES (1991, p.17) aponta para esse crescimento demográfico dos povos indígenas ao afirmar que "há fortes indícios de que as populações indígenas sobreviventes vêm crescendo nas últimas três décadas, surpreendendo as expectativas alarmantes e as consideradas mais realistas (...) de tempos atrás."

\section{A NOÇÃO DE PESSOA E A FABRICAÇÃO DO CORPO}

De acordo com SEEGER et al (1987, p.11), devemos creditar a Lowie e a Lévi-Strauss a apresentação do pensamento indígena sul-americano ao circuito conceitual mais amplo da antropologia, e, em termos de etnografia, se excetuarmos Nimuendajú, foi só depois de 1945 que os estudos descritivos mais detalhados de sociedades tribais brasileiras tiveram início, sendo que só mais recentemente é que se iniciou a elaboração teórica desse material. Assim, atualmente, segundo os referidos autores, podemos afirmar que a etnologia do Brasil já alcançou uma certa maturidade, desenvolvendo teorias e problemáticas originais.

Segundo esses antropólogos, a etnologia dos grupos tribais brasileiros tem trazido contribuições à antropologia como um todo, sendo que, segundo os mesmos, a originalidade das sociedades tribais brasileiras reside na elaboração particularmente rica da noção de pessoa, com referência especial à corporalidade, isto é, o lugar que o corpo humano ocupa na visão que essas sociedades indígenas fazem de si mesmas enquanto idioma simbólico focal. Portanto, a noção de pessoa e a questão da corporalidade são tidas como caminhos básicos para a compreensão da organização social e da cosmologia dessas sociedades tribais, visto que a grande 
maioria dessas sociedades privilegia as ideologias da corporalidade na elaboração de suas cosmologias. Conseqüentemente, de acordo com os referidos autores, ao se privilegiar a corporalidade, o objetivo é entender a definição e a construção da pessoa em uma dada sociedade indígena em questão, ou seja, quando perguntamos sobre o lugar do corpo estamos iniciando uma indagação sobre as formas de construção da pessoa, sendo que, a esse respeito, o trecho que segue é bastante esclarecedor:

"Não há sociedade humana sem indivíduos. Isto, porém, não significa que todos os grupos humanos se apropriem do mesmo modo desta realidade infra-estrutural. Existem sociedades que constroem sistematicamente uma noção de indivíduo onde a vertente interna é exaltada (caso do Ocidente) e outras onde a ênfase recai na noção social de indivíduo, quando ele é tomado pelo seu lado coletivo: como instrumento de uma relação complementar com a realidade social. É isso que ocorre nas sociedades chamadas tribais e é aqui que nasce a noção básica de pessoa”. (SEEGER et al, 1987, p.13)

Agora, depois de termos apresentado essas primeiras idéias sobre as formas de construção da pessoa nas sociedades indígenas, julgamos conveniente chamar a atenção do leitor para o fato de que sob a concepção de pessoa se escondem importantes diferenças teóricas, dentro da antropologia. No que tange às sociedades indígenas brasileiras, os mencionados autores defendem o argumento de que os conceitos antropológicos que procuram definir a estrutura dos grupos sociais e da inter-relação entre os grupos não dão conta dos traços estruturais dessas sociedades ameríndias, e também chamam a atenção para o fato de que, na maioria das sociedades indígenas do Brasil, a questão da corporalidade ocupa uma posição organizadora central, sendo que, neste sentido, citam a título de ilustração sociedades tais como a Jê, a Xinguana e a Tukano. (idem, 1987, p.16-17, 20-22)

Para as sociedades indígenas da América do Sul, a pessoa, como entidade simbólica, é mais importante que o grupo, e a relação com o corpo e com os nomes, por sua vez, é mais importante que o acesso à terra ou às pastagens. Assim, os autores chegam à conclusão de que a noção de corporalidade é uma categoria fundamental para as sociedades sul-americanas. Consequientemente, segundo os mesmos, a antropologia deve ser repensada com os olhos dos índios brasileiros, sendo que, para tanto, a noção de pessoa e o conceito básico de corporalidade devem ser tomados como idioma focal, pois, só assim, os tradicionais cortes etnocêntricos em instâncias sociais como "parentesco", "economia", "religião" serão evitados. (idem, 1987, p.24 e 26)

CASTRO (1987), por sua vez, ao analisar a fabricação do corpo na sociedade xinguana, informa-nos que pretende especificar alguns dos pontos sugeridos pelos autores anteriormente abordados (Anthony Seeger, Roberto Da Matta e o próprio Eduardo de Castro), com base nos dados coletados junto aos Yawalapíti, um grupo indígena que participa do sistema social alto-xinguano. Ao falar em "fabricação do corpo", ele esclarece que esta é entendida como atividade huma- na, intervenção consciente sobre a matéria. $O$ autor verificou que entre os Yawalapíti, as transformações do corpo e da posição social são uma e a mesma coisa, sendo que a natureza humana é, por conseguinte, literalmente fabricada, modelada, pela cultura, ou seja, o corpo é imaginado, em vários sentidos, pela sociedade. (CASTRO, 1987, p.32)

Para Castro, o complexo da reclusão é entendido como um aparelho de construção da pessoa xinguana (neste ponto, acreditamos que seja oportuno esclarecer que o autor recorre à expressão "pessoa xinguana" porque ele assume a hipótese de que as mesmas idéias que expõe sobre os Yawalapíti também estão presentes na ideologia e na prática das demais aldeias do Alto Xingu), porquanto que é através dele que os papéis sociais são assumidos: "que o idioma da reclusão seja sobretudo um idioma da corporalidade, isso nos indica o papel central que a imagem do corpo desempenha na elaboração da persona xinguana." (idem, p.36) Deste modo, sintetizando suas análises sobre a fabricação/reclusão na sociedade xinguana, o autor afirma:

\begin{abstract}
"Toda esta lógica (...) constitui o corpo xinguano em sua trajetória do nascimento à morte e se manifesta com mais força nos momentos de reclusão (...) Assim, o que se passa 'dentro' do corpo é de interesse imediato para a sociedade, que não se limita a inscrever à superfície do corpo suas marcas gráficas. (...) Fabricação/reclusão opõe-se (...) à decoração/exibição; os seres em reclusão não se pintam nem se adornam, estão 'nus'. Tal oposição marca a vida xinguana em elevado grau, que se desenrola como oscilação entre estes dois momentos complementares e necessários. Esta dialética ilumina os modos de emergência da individualidade (em sentido lato) na sociedade xinguana. (...) Aquilo que distingue os indivíduos - seus corpos - transforma-se, na reclusão, naquilo que os identifica." (idem, p.38-39)
\end{abstract}

Finalizando essas nossas considerações gerais sobre as sociedades indígenas, podemos afirmar que é possível conhecer vários aspectos de uma dada cultura indígena através da estética ou da pintura no corpo como, por exemplo, à qual clã o indivíduo pertence, qual a sua hierarquia no grupo, etc. Conforme assinalam VIDAL \& SILVA (1992, p.279), diversas culturas indígenas ordenam e expressam sua percepção do mundo e de si mesmas por meio da criação artística e da expressão estética, ou seja, é através da arte gráfica que determinadas culturas indígenas veiculam imagens que representam suas principais concepções sobre a vida social e sobre suas relações com a sociedade, a natureza e o cosmo.

\section{CONSIDERAÇÕES FINAIS}

Ao estudarmos as sociedades indígenas, ou seja, os povos ditos "primitivos", percebemos que estes povos apresentam uma rica diversidade cultural, apesar de toda a pressão que os chamados "civilizados" exerceram e continuam exercendo sobre eles. 
Seguindo, então, alguns dos ensinamentos deixados por Lévi-Strauss, tentamos, assim como ele, buscar as diferenças através das semelhanças $\mathrm{e}$, deste modo, procuramos demonstrar que existe uma universalidade das mentes humanas e que, sem essa semelhança psíquica, os homens não teriam desenvolvido suas capacidades simbólicas, ou seja, as diferenças ou diversidades culturais têm sua origem naquilo que podemos chamar de "a singularidade humana": a capacidade de simbolizar e de aprender.

Concluímos, portanto, que os homens de todas as sociedades, isto é, tanto os "primitivos" ou indígenas como os "civilizados" ou ocidentais, se movem entre dois modos de conhecimento e ação, um simbólico/mitológico e outro empírico/racional, sendo que estes dois modos coexistem, entreajudam-se e estão em constante interação. Assim, dizer que as sociedades primitivas se movem pautadas apenas no conhecimento místico é uma incoerência, pois toda renúncia ao conhecimento empírico ou racional conduziria os homens à morte. Do mesmo modo, dizer que as sociedades civilizadas se movem baseadas somente no conhecimento técnico ou racional, é outro desacerto, já que a renúncia às crenças humanas seria uma forma de negação da própria essência cultural do homem.

\section{REFERÊNCIAS BIBLIOGRÁFICAS}

CASTRO, Eduardo B. Viveiros de. "A fabricação do corpo na sociedade xinguana”. In: OLIVEIRA FILHO, João Pacheco de. (org.). Sociedades indigenas e indigenismo no Brasil. Rio de Janeiro: Marco Zero, 1987. p.31-41.

CUNHA, Maria Manuela Carneiro da. "Parecer sobre os critérios de identidade étnica". In: COMISSÃO PRÓ-ÍNDIO/SP. $O$ índio e a cidadania. São Paulo: Brasiliense, 1983. p.96-100.

GOMES, Mércio Pereira. Os índios e o Brasil: ensaio sobre um holocausto e sobre uma nova possibilidade de convivência. Petrópolis: Vozes, 1991.

GOULD, Stephen Jay. Darwin e os grandes enigmas da vida. Lisboa: Europa-América, 1978.

LARAIA, Roque de Barros. "Os estudos de parentesco no Brasil". BIB, n.23, p.3-17, 1987.

LÉVI-STRAUSS, Claude. Antropologia estrutural. Rio de Janeiro: Tempo Brasileiro, 1967.

MELATTI, Julio Cezar. "A antropologia no Brasil: um roteiro". BIB, n.17, p.3-52, 1984.

RAMOS, Alcida Rita. Sociedades indígenas. São Paulo: Ática, 1995.

RICARDO, Carlos Alberto. "'Os índios' e a sociodiversidade nativa contemporânea no Brasil”. In: SILVA, Aracy Lopes da \& GRUPIONI, Luís Donisete Benzi. (orgs.). A temática indígena na escola: novos subsídios para professores de $1^{\circ}$ e $2^{\circ}$ graus. Brasília: MEC/MARI/UNESCO, 1995. p.29-60.

RODRIGUES, José Carlos. Antropologia e comunicação: princípios radicais. Rio de Janeiro: Espaço e Tempo, 1989.

SEEGER, Anthony; DA MATTA, Roberto; CASTRO, Eduardo B. Viveiros de. "A construção da pessoa nas sociedades indígenas brasileiras". In: OLIVEIRA FILHO, João Pacheco de. (org.). Sociedades indigenas e indigenismo no Brasil. Rio de Janeiro: Marco Zero, 1987. p.11-29.

VIDAL, Lux \& SILVA, Aracy Lopes da. "Antropologia estética: enfoques teóricos e contribuições metodológicas". In: VIDAL, Lux. (org.). Grafismo indígena. São Paulo: Studio Nobel, 1992. p.279-293. 